\section{MELHORES DO MUNDO EM ASSISTÊNCIA À SAÚDE: APRENDENDO COM BOAS PRÁTICAS}

\author{
WHICH COUNTRY HAS THE WORLD'S BEST HEALTH CARE? \\ Ezekiel J. Emanuel. New York, USA: Public Affairs, 2020.466 p.
}

Ranquear pode ser um bom início para uma análise comparativa. Vivemos em uma sociedade na qual a medição, quantificação e ranqueamento tornaram-se usuais, desde pela pura curiosidade (10 melhores montanhas-russas) até para a criação de dispositivos que facilitam a tomada de decisão (melhores MBA). Quando um autodenominado ranqueador compulsivo é um especialista em políticas públicas de saúde, o resultado pode ser encorajador. Não pelo ranking, mas pelo modelo proposto de análise comparativa entre sistemas de saúde em diferentes países. Pesquisadores da gestão da saúde conhecem a importância dessa análise para o desenvolvimento da área, mas sabem dos desafios para realizá-la devido à complexidade desses sistemas e da não padronização dos dados para comparação. A obra apresenta parâmetros para comparar 11 países, ressaltando desafios e boas práticas de gestão de saúde no mundo.

Ezekiel J. Emanuel é professor e codiretor do Healthcare Transformation Institute na Universidade da Pensilvânia. Além da sua atuação acadêmica, foi conselheiro do diretor-geral da OMS e diretor do departamento de Bioética no National Institute of Health dos EUA. Escreveu e editou 14 livros e mais de 300 artigos acadêmicos, além de ser autor de diversos artigos em jornais.

Apesar da paixão por ranquear, considera inapropriado ranquear sistemas de saúde, visto que a sua estrutura depende da ênfase que cada país coloca nas dimensões que o englobam. Se ranquear não é apropriado, uma análise comparativa traz quatro lições valiosas: (1) nenhum sistema de saúde é perfeito, pois os desafios que o cuidado com a saúde engendra para todos os países fazem com que todos apresentem dificuldades a serem solucionadas; (2) pode-se aprender com os problemas comuns que são enfrentados mesmo pelos países, cujos sistemas são considerados excelentes; (3) não é possível definir qual o melhor sistema de saúde, mas pode distinguir-se os bons dos não minimamente aceitáveis; (4) ficam mais claras as dimensões de análise dos sistemas de saúde e as experiências de outros países em cada dimensão que podem iluminar caminhos futuros para políticas públicas que os aprimorem.

A análise comparativa envolve 11 países: Austrália, Canadá, China, França, Alemanha, Holanda, Noruega, Suíça, Taiwan, Reino Unido e EUA, escolhidos intencionalmente considerando suas diferenças, alguns com financiamento público, outros privado, com seguro obrigatório ou não; esses países aparecem com mais frequência nos debates 
internacionais sobre o tema. Todos eles, por algum motivo, poderiam ser alçados a modelo a ser seguido.

Cada país foi avaliado em oito tópicos: (1) história; (2) cobertura; (3) financiamento; (4) pagamento; (5) entrega dos cuidados de saúde; (6) regulamentação dos medicamentos e sua precificação; (7) recursos humanos e (8) futuros desafios. A história é fundamental para se compreenderem os sistemas de saúde, pois um dos argumentos é o de que a dependência do caminho (path-dependence) é fator que dificulta a implementação de soluções que deram certo em outros países. Além disso, dois pontos merecem destaque: (1) a existência de sistemas universais de atendimento à saúde é recente; (2) depois de implementada a universalização, em nenhum caso ocorreu a reversão do processo. 0 caso brasileiro é semelhante, com universalização recente e não reversão do processo até o momento. Conforme destacam Machado, Baptista e Lima (2012), a universalização em nosso país ocorreu na Constituição de 1988, na qual a saúde passa a ser reconhecida como um direito, cuja universalização é garantida pela criação do Sistema Único de Saúde (SUS). As décadas seguintes são caracterizadas pelas batalhas para sua efetiva implementação.

Discutem-se também sete desafios comuns aos países: pressão dos custos; alto preço dos medicamentos; redução de ineficiências e tratamentos desnecessários; coordenação no tratamento dos pacientes; incompatibilidade entre características de instituições de atendimento, centradas em atender traumas e infecções, e a necessidade de cuidados continuados dos pacientes sofrendo de doenças crônicas; cuidados de saúde mental; e, por fim, cuidados com a velhice e como se vai pagar por isso. Esses desafios seguem uma tendência de agravamento, em virtude do aumento da média de idade da população e do desenvolvimento de tecnologias mais caras de tratamento. Todos os desafios afetam o Brasil (Saldiva, 2018); em alguns deles, servimos de referência, tal como o programa Estratégia Saúde da Família, reconhecido internacionalmente em relação à coordenação no tratamento de pacientes e nos cuidados continuados (Machado, Melo, \& Paula, 2019).

Para finalizar, o autor relaciona a pandemia com os sistemas de saúde argumentando que não podem ser fundidos, pois a resposta à pandemia requer mais do que um sistema de saúde funcional: "The adequacy of the response depends upon political judgment and leadership to rapidly institute public health measures and the competence of the public health infrastructure to implement them effectively and swiftly". Sem a vontade política para implementar medidas necessárias, não existe possibilidade de resposta positiva do sistema, lição que parece não ter sido aprendida pelo governo brasileiro nesta pandemia.

Um ponto que requer reflexão é a falta de destaque às disputas políticas na construção dos sistemas. Apesar do doutorado em Filosofia Política e de a contextualização histórica mostrar as disputas entre grupos de interesse, o autor destaca a dependência do caminho no seu sentido econômico, amenizando os desafios políticos. 0 caso brasileiro evidencia disputas políticas envolvendo ações de saúde voltadas para a coletividade e saúde pública, e outras de caráter privado (Machado et al., 2012), culminando em um sistema partilhado entre a universalização do sistema público e o setor de saúde suplementar, privado. Entre os países com universalização do sistema de saúde, o Brasil é o único em que os gastos privados são maiores que os gastos públicos com saúde, apesar de o último atender parte maior da população (Silveira, Noronha, Funcia, Ramos, Moraes, Castro \& Noronha, 2020).

Outra crítica é que, apesar de defender a universalização dos sistemas de saúde, o autor aceita que todas as dimensões analisadas possuem igual valor, e qual deva receber mais atenção é uma questão de escolha. A universalização da saúde no Brasil decorreu da luta política do Movimento Sanitário pela democratização da saúde (Cruz, 2017), a qual não termina com a universalização incrustada na Constituição. As disputas continuam com a desregulamentação da saúde complementar (Machado et al., 2012) e propostas de criação de planos de saúde “acessíveis" para a população de baixa renda.

O livro traz um excelente modelo de análise comparativa, escrito em linguagem acessível. As contribuições para área da Administração Pública da saúde vão da sistematização do modelo de diagnóstico até a descrição das boas práticas adotadas que melhoram a eficiência dos sistemas. Além disso, são apresentadas boas práticas de gestão pública e privada, especialmente inovações na gestão de custos e na criação de incentivos para a gestão mais eficiente dos recursos. É direcionado a acadêmicos, professores e pesquisadores das áreas de saúde, economia e gestão, que buscam uma análise comparativa sintética para utilizá-la na discussão dos problemas enfrentados pelo Brasil. Para Ezekiel, a maneira adequada para enfrentar os desafios que o acesso à saúde de qualidade apresenta está na capacidade de otimizar a gestão dos recursos investidos sem perder de vista o objetivo final que é o bem-estar das pessoas. 


\section{REFERÊNCIAS}

Cruz, S.A.M. (2017). A criação do Sistema Único de Saúde. Rio de Janeiro, RJ: Gramma.

Machado, C. V., Baptista, T. W. F., \& Lima, L. D. (2012). Políticas de saúde no Brasil. Rio de Janeiro, RJ: Editora Fiocruz.

Machado, H. S. V., Melo, E. A., \& Paula, L. G. N. D. (2019). Medicina de Família e Comunidade na saúde suplementar do Brasil. Cadernos de Saúde Pública, 35(11). doi:10.1590/0102-311Xooo68419.
Saldiva, P. (2018). Saúde. In: J. Pinsky (Org.), Brasil: O futuro que queremos (pp. 25-41). São Paulo, SP: Contexto.

Silveira, F. G., Noronha, G.S., Funcia, F.R., Ramos, R.L.O., Moraes, R.M., Castro, L.C., \& Noronha, J.C. (2020). Os fluxos financeiros no financiamento e no gasto em saúde no Brasil. Rio de Janeiro, RJ: Fundação Oswaldo Cruz.

\section{CONTRIBUIÇÃO DE AUTORIA}

Maurício Reinert foi o único autor da resenha, sendo responsável por sua concepção, redação e revisão final do manuscrito. 